\title{
Editorial: Applied Practices - Perspectives From the Field
}

The two articles in the Applied Practices section of the current journal provide interesting views of the role of school psychologists and school counsellors in interventions directly facilitating children's development, progress and skills within schools.

The first article, by Davis, Sheldon, and Colmar, is a pilot study exploring the effectiveness of embedding working memory strategies within a primary school classroom in Sydney, New South Wales, in increasing academic work and engaged behaviour. Memory Mates is a set of research-based, easily adopted approaches that children can utilise to better manage their attention and learning, with a focus on working memory skills. School counsellors are well placed to implement such work, with evaluation, in their own schools.

The second article evaluates a program, Healthy Mindsets, which aims to build resilience as a preventative construct in children aged 9 to 14 years. The study explored the effectiveness of the program, incorporating child and parent/carer responses, with overall positive ratings. Facilitators' responses were also explored to ensure optimal use of this new program.

I am delighted with the response to date in papers being submitted and would welcome many more. To remind colleagues, Applied Practices' requirements are noted below. In this section of the journal, articles need to have an applied focus, with scope for colleagues to offer papers such as:

- small-scale evaluations of practice, where the findings are interesting and noted as preliminary and worthy of further exploration, even if these are not methodologically at the standard required for contributions to the main journal (e.g., no control group);

- conceptual or research literature reviews with implications for practice, with a specific reflective argument addressing practice, possible provocatively;

- linked case studies in therapeutic and learning and behaviour areas of intervention integrated around a common theme.

Sources might include reports from presentations; work in progress where preliminary data is reported, allowing the author to submit full findings later; and adapted students' assignments. Papers are refereed.

Review guidelines include the following:

1. The article is of interest and relevance to members. 
2. It is well written, properly referenced using APA 6th edition guidelines, and is grammatical.

3. It has a literature base, albeit small, supporting the work's findings and/or thinking.

4. It is approximately 3,000 words.

5. It may contain a 120 -word abstract.

6. It has a clearly articulated argument and looks to future directions; thus, the work is beyond simple description, and needs to be analytical in its approach.

\section{Dr Susan Colmar}

Editor, Applied Practices Section within the Australian Journal of Guidance and Counselling Faculty of Education and Social Work, Room 805, Education Building A35, The University of Sydney NSW 2006, Australia Telephone: +6129351 6265; Fax +61293512606

Email: susan.colmar@sydney.edu.au 